\title{
Impact Factors for Learner Motivation in Blended Learning Environments
}

\author{
http://dx.doi.org/10.3991/ijet.v7iS2.2326 \\ Mag. Ing. Alexander Schober, StR Dr. Lars Keller \\ Innsbruck University, Innsbruck, Austria
}

\begin{abstract}
Literature on the use of New Media and Learning Management Systems (LMS) in problem based learning settings suggests positive effects on learner motivation. In a two year study by the Institute for Geography at Innsbruck University, 176 pupils aged between 15 and 19 years from four schools in four countries were surveyed and questioned regarding their motivation. Their task was to do a comparative regional study on the Quality of Life (QOL) of youths in their respective region. To facilitate communication and collaboration, the LMS Moodle was used. The current findings suggest that their average motivation was high during certain periods but lower than could be expected on a long term scale. Amongst the factors that influenced the learners' motivation, the most important ones were: Features and usability of the LMS in use, local parameters at school and the general workload that the students were exposed to. While the latter cannot be directly influenced and is not a specific problem of Blended Learning, it is possible to improve the performance of LMS and the local parameters. It can therefore be expected that the average learner motivation will improve with the further development of LMS in the near future.
\end{abstract}

Index Terms-Moodle, Moderate Constructivism, Blended Learning, Technology Enhanced Learning, Problem Based Learning

\section{INTRODUCTION}

Literature [e.g. 2] suggests that the use of New Media and Learning Management Systems (LMS) in problem based learning settings has positive effects on learner motivation.

In our study, we found that the average long-term learner motivation was lower than could be expected. We therefore focused our research on factors that influence learner motivation and tried to identify some of the obstacles that prevent Blended Learning from unfolding its full potential in day-to-day school life. We also tried to make suggestions how they could be removed and thereby help practitioners and researchers alike to improve the quality of teaching with New Media. The paper at hand aims to give a brief summary of our present hypotheses. As the study is not yet finished, our results must still be considered preliminary.

\section{SETTING}

The Sparkling Science project "LIFE 'Quality?“ is run by the Institute of Geography at Innsbruck University and four schools in Bavaria, the Engadin, Northern Tyrol and Southern Tyrol $^{1}$. 176 pupils, six teachers and the researchers participate in the project that ends in Septem-

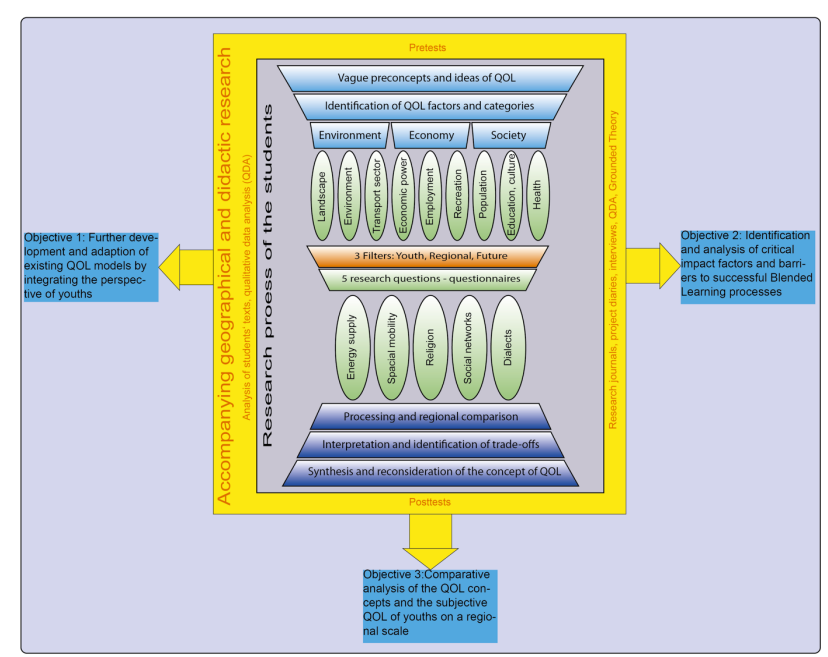

Figure 1. Research design (Schober, 2011)

ber 2012. Together, they form "a community of learners" [10] that explores the potential of Blended Learning over a two year period.

The 15- to 19-year old students are working in five multi-national teams consisting of three students from three regions each. Cooperation and collaboration between the teams are facilitated by the LMS Moodle (version 1.9.15) and several embedded Internet applications and apps such as Google Docs. The work groups' task is to do empirical research in their respective region and to compile their results for a comparative study. The general topic for their research is Quality of Life (QOL, see Figure 1). Within this broad field, students were given the option to autonomously decide on the subtopics of their teams. At the beginning of each work phase, they were given a necessary minimum of instruction. After that, teachers and researchers assist, moderate and evaluate the work process of the youths.

Without doubt, the collaborative collection of empirical data and the interpretation and presentation of the results constitutes a challenging and problem oriented task for learners in this age bracket. The task is authentic because it is organized according to the standards for scientific work. To plan their research and to coordinate the work process in three countries, students are required to actively deal with their subtopics and collaborate closely with their peers. Thus, a strong emphasis on autonomy and the social component is given. As the project-related evaluation [18] shows, all six of the quality criteria for the design of virtual learning modules that Arnold et al. [2] summarized are met. 
While the students focused on aspects of QOL, one of the researchers' various aims was to investigate this autonomous, technology enhanced learning process. Thus, multiple research goals could be targeted with this setting (see Figure 1). The present paper will concentrate on the analysis of impact factors for technology enhanced learning processes. For more detailed descriptions of the QOL-aspect of the project see [13] and [14].

\section{DATA AND METHODS}

Because incidents in classrooms occur simultaneously and are mostly irreproducible, reliable data about individual learning processes in school environments are difficult to collect [1]. Traditionally, empirical classroom research and action research are therefore often strongly based on research journals i.e. written documentations of teachers' observations, experiences and reflections. Although these journals constitute powerful and valid research instruments [1], they naturally present only a limited perspective.

In our study, we draw on a multitude of data sources. The collection of this extensive corpus of data is made possible by the central role that the LMS Moodle plays in the students' learning processes. To a large extent, this data is qualitative and primarily text-based: For example, all participating students are obliged to write learning journals ("project diaries" as they are called) throughout the whole school year. They prove to be be very valuable tools to gain insights into the subjective learning processes. Teachers also document their observations in journals, thereby adding an outside perspective.

While the journals are used to monitor continuous individual progress, Pre- and Posttests, carried out at the beginning and at the end of each school year allow for a comparison of the Status Quo before and after participation in the project.

A number of interviews further broaden the qualitative database. At the end of each school year, personal interviews with all participating teachers in their role as experts were conducted (9 interviews). In addition, eight guided group interviews with groups of ten students on average are conducted.

All interviews, the four workshops with the pupils in Innsbruck as well as a selection of team meetings and discussions in class were digitally recorded and then transcribed. The transcriptions were done according to the guidelines of Dresing and Pehl [7]. To further enhance the validity of our qualitative with quantitative data, we analyzed Moodle's log files statistically. Thus, we gained information about the average usage of the platform. We also selected a sample of 31 students by choosing 2 "high performers" and two "low performers" from each class and inquire into their respective handling of Moodle and the motives behind it [18].

Technically, this computer aided qualitative data analysis is done with the Software MAXQDA. It allows coding of large amounts of text and is able to handle quantitative data as well. Questionnaire data and texts were exported from Moodle in csv and txt format. During preprocessing, spelling mistakes in the texts were corrected and the raw data anonymized by replacing all names with six digit numerical codes. The preprocessed data was then imported into MAXQDA. A citation format for artifacts was introduced: “LJ 138734, 1, 36" refers to paragraph 36 from the learning diary of student number 138734, first project year. All quotes in this paper were translated by the authors.

Grounded Theory (GT) [9] provides the methodological background for the exploration of this diverse and substantial amount of data. Qualitative data is broken down into chunks of text that are then coded with labels. These codes are then rearranged and combined into concepts, which can be analyzed for interrelations and/or conformities. Usually, the composition of (code, theoretic and operational) memos accompanies the several stages of this coding process until finally, theories or theses that are empirically funded (i.e. "grounded in the data") emerge from the processed data.

While at present the majority of the data was coded by one researcher only, some of it was already analyzed by three persons independently, thus providing intercoder reliability.

The consideration of a variety of different data sources and types as well as the triangulation of the results of a team of researchers enhances the validity of our findings.

\section{PRELIMINARY RESULTS}

At the current stage, not all tests have yet been carried out. Furthermore, the investigation into the collected data and the coding process are still going on. Thus, the following hypotheses must be considered preliminary.

Due to the limited length of this paper, only one or two artifacts are quoted as evidence for the respective hypothesis. For a comprehensive presentation of our results see [12].

\section{A. Average Learner motivation is high during certain periods but lower than could be expected on a long term scale.}

A number of artifacts indicate that students were highly motivated during certain periods of the project:

"it is fun to think about research questions and to deal with a special topic. I did some research and came up with interesting studies. I can really say that the topic is interesting and I like to continue working with it." (LJ 137314, 2, 27)

It should be pointed out that this motivation is genuinely instrinsic: the results of the students research were not graded, so they had no external incentive to do more than was requested of them. Even the teachers were at times surprised by their pupils behavior, as this quote shows:

"Amazing: the eight pupils sit down and begin to work. Some of them improved their diagrams at home. They even managed to analyze the open questions by filtering the answers.” (PT L3, 2, 51-53)

However, pupils frequently mentioned a lack of motivation in their journals. In most cases, they justified this with the massive work load they have to handle at school. Teachers attributed the situation to the socialization of the pupils: According to them (and some of the students) it is very hard for youths to concentrate their efforts for a period of several months because they are not used to it. Regarding the positive motivational effects of Blended Learning we tend to subscribe to Kerres' and Gorhan's view: According to them, the use of 
New Media can boost learner motivation on a short term basis, but it declines shortly afterward [quoted in 8].

\section{B. Usage of LMS outside of school marginal.}

One of the most popular arguments for the use of LMS in a school context is the flexibility they offer. Our data indicates that pupils do not see this as an opportunity and do - with few exceptions - not embrace the option to "learn anytime, anywhere".

Figure 2 shows the total number of productive accesses to the Moodle platform outside of lessons during the first year of the project. Productive accesses were defined as "forum entry" or "forum update", "wiki edit", "file upload”, “journal entry” or “journal update”. Cases are plotted on the x-axis, the number of accesses on the $y$ axis. Only four students accessed the platform more than 20 times during one school year, the majority of learners used Moodle actively less than ten times.

A chronological analysis shows that activity peaks at the end of the Webquest phase, when students were discussing their subtopics and around the first workshop in Innsbruck where all students met in Innsbruck. Apart from these two peaks, the activity of the students outside of their lessons is generally low throughout the year.

These observations are in line with Mayr et al. [16] who relate that "the LMS was more often accessed during lessons than from outside school. Both the teachers' and the learners' interest in location independent synchronous and asynchronous learning phases was not very high.”

\section{Pupils consider Moodle's tools for communication inadequate for efficient communication.}

Conducting research together with partners in three countries requires a fair amount of online communication between the members of the work groups in different countries. Like most LMS, Moodle offers several tools to handle these communication needs. Our experience shows that students did not consider any of these tools suitable and as a result did not communicate effectively via the learning management system.

Synchronous Communication in chats was not a good option, because "no one is ever online" as one student put it. Indeed, because the lections took place at different times, it was not possible to establish regular communication via Moodle's chat function. Asynchronous communication with the forum module also did not work satisfactorily. 13 of the 16 interviewees expressed critique concerning the communication via online forums. Eight of these explicitly stated that it is "very difficult" to achieve any consensus using this instrument.

Because the given options were unsatisfying, many learners expressed the wish to use Facebook for communication:

"The first thing we did when we returned to our table after lunch [at the workshop] was to exchange our Facebook contact details. This way, we will be able to stay in touch much better than we were with Moodle.” (LJ 137483, 1, 26)

Several observations and artifacts show that some of the pupils did use Facebook to discuss the project with their peers. We interpret this behavior to that effect that there is a need for communication within the Work Groups but Moodle does not provide the tools to meet this

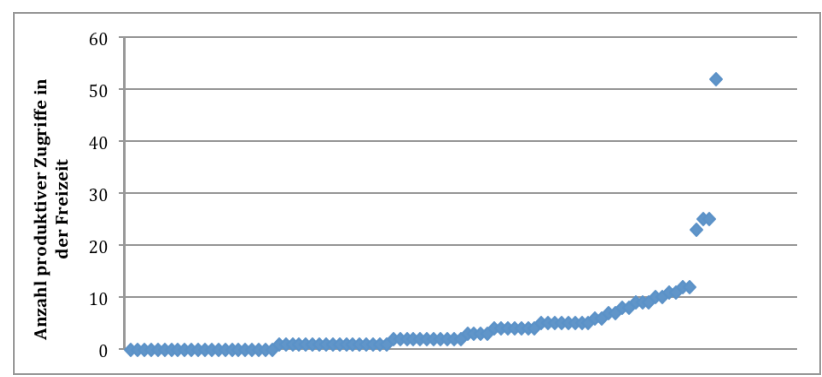

Figure 2. Number of productive accesses to the Moodle platform outside of the lessons during project year one (Neyer, 2012, adapted)

need. When asked about suggestions for the improvement of Moodle, several students suggested connecting it with Facebook because this would make it easier for them to "follow the events".

One reason why Moodle cannot meet the needs of young learners is that is - like most LMS - based on the assumption that Email is the preferred way of digital communication for its users. As a consequence, messages like the daily forum digests are forwarded to the users as Emails. If, as both our experience and current studies show, this is not the case, then the information is delayed or lost. Only 68 per cent of all 16 to 17 year olds read their Emails more than once a week [17]. Several of our pupils stated that they never read their Emails.

The second factor that influences the amount and the quality of communication that takes place in virtual work groups is the willingness of the users to communicate. We found that this willingness is highest shortly before and after attendance phases and events. The number of forum posts increased significantly shortly before and shortly after the workshops in Innsbruck and was almost zero between them. This is especially true for the kick-off workshop. We therefore strongly recommend to plan a sufficient number of workshops and to organize a kick-off event as soon as possible to motivate the participants to engage in online conversation and collaboration. To optimize the communication process, we also recommend supplementing the standard communication tools of any LMS by offering alternative channels like Skype or Facebook.

\section{Usability of Moodle needs to be improved.}

Many users criticized the user interface of Moodle. They reported that they consider it confusing. To them, it was not always clear where certain documents and functions could be found. They also complained that it often requires many clicks to complete an action. Repeatedly, students complained that Moodle is not intuitive and much too complex. In the personal interviews, seven pupils made statements that were later summarized in the category "LMS not helpful and cumbersome".

For some of the learners, the perceived disadvantages and shortcomings of Moodle were a constant source of frustration and eventually led to a decrease in their motivation for the project. In our opinion, this problem is hard to tackle because the students tend to compare the performance of a Learning Management System with that of the professional platforms they use in their spare time. Of course, these commercial platforms are well funded and are operated by professional developers and companies. Learning Management Systems like Moodle 
or OLAT on the other hand are open source products that depend on a small developer community. Even if, which is likely, their performance will strongly improve in the near future because of increased demand, it will never match that of their commercial counterparts and the expectations of young learners.

\section{E. Computer competence of students and teachers is less than expected.}

Since Mark Prensky has coined the term "Digital Natives" more than ten years ago [19], a lot was written about this generation of learners. Repeatedly, his thesis was questioned and dismissed as myth. Sometimes, the generation in question was referred to as "Digital Naives".

We too observed difficulties regarding the use of New Media which do not justify the label "Digital Natives". Although 60 per cent of the students answered that they had "a little" or "some experience" with Learning Management Systems (such as blackboard, OLAT or Moodle) in the Pretests, the majority of them had difficulties to handle communication in forums or edit tables within a simple text editor.

When it came to using Software creatively and productively, solving problems autonomously or acquiring skills independently, some of the learners reached their limits. Even more surprisingly, many had difficulties using the elementary functions of standard office software like Microsoft Excel or Google Docs.

"Today we calculated average values and and totals in our Excel sheets. In the process, we encountered big problems, because the program displayed rhombs instead of figures. We were therefore forced to use the calculator.” (LJ 139407, 2, 22-23)

"In the beginning, the preparation of the final slideshow presentation was relatively demanding, because we did not know how to use the Software." (LJ 137574, 2, 26-27)

Of course, these quotes represent extreme cases. Our sample also included highly competent students. However, they were rather the exception than the rule. Considering that these pupils will shortly complete secondary education and receive their Matura or Abitur (i.e. the general qualification for university entrance) this is a remarkable observation. We would therefore suggest rethinking expectations towards this generation of learners and considering to carry out an introductory phase before actually working with Learning Management Systems in class.

In the course of the project we also observed that the media competence of the teachers was in some cases not sufficient to support the learning process of the pupils and solve upcoming technical problems on the spot. Their willingness to deal with the technical aspect of the project was also very limited. Two of the six participating teacher did not log in once on the Moodle Platform. None of them used Moodle actively. Journal entries show that they are aware of this problem and trace it back to a lack of time.

"For me, it was difficult. Let me say first of all that I was not very involved in the project and what went on there and how the platform works. I did not have the time to familiarize myself with the platform." (Interview L6, 1, 5)

Although empirical studies offering up-to-date information about the use of computers in schools are lacking, a Bavarian study which states that only 12 per cent of all teachers use computers from time to time, whereas 64 per cent never use them for teaching $[3,4]$ seems to comply with our findings. As it is a precondition for successful learning with New Media that the teachers are experienced within this field, we are of the opinion that the topic "Blended Learning" should become an obligatory element of teacher training.

\section{F. Local parameters at schools can be limiting factors in E-learning processes.}

The last impact factor that influences the motivation of learners in is often neglected in scientific studies, although it can potentially be very limiting for otherwise well designed Blended Learning environments. Local parameters such as hard- and software facilities or rooms influence the learning process in a number of ways.

One effect of less than ideal local parameters is the demotivation of learners. Only one of our four partner schools offered computer rooms with up-to-date hardware and fast internet access. In the other three, learners often had to wait until webpages were loaded. This not only slowed the work process, it also led to considerable frustration:

"Initially, we had technical problems, which resulted in a reduction of our concentration and motivation" (LJ 138796, 2, 14-15)

"It was difficult to import the graphics in the presentation. We had to wait for very long until it finally worked. This clouded our good mood considerable. It is nicer to work at the University because the chairs are more comfortable and the computers faster." (LJ 138289, 2, 64-65)

One of our partner schools is certified as an "eLSA" school ("eLearning im Schul-Alltag") [6]. None of the classrooms at this school feature any computer equipment. Interaction with new media is limited to the computer rooms, which are located in the cellar. Because they offer no view and tend to be cold, going there is not popular amongst the students. A total of 16 computers are available for classes of up to 27 and more students. Alignment and spacing of the desks is tailored for traditional learning arrangements and makes productive group work virtually impossible. When we decided to invite these pupils to work at University instead of school, almost all of them reported that this had a very positive effect on their motivation.

"Today, our job was the same as last lesson, only it was much easier for us. I also noticed that the motivation was much lower at school than here at University!” (LJ 139186, 2, 30-32)

While these problems can be attributed to a lack of (hardware) resources, the Software configuration and security policies in schools can also limit the potential of E-Learning. We found that schools tend to implement restrictive firewalls, which not only block malware, but also prevent access to useful tools for collaborative work like Google Docs or bubble.us. As the teachers are usually not given the rights to change any configurations it is impossible to react quickly to this situation, if it leads to problems. Because of lower costs, schools also tend to find open source products like Libre Office attractive. In case they decide for open source software, it may be 
problematic when data shall be exchanged with other users.

\section{CONCLUSION}

"Blended learning”, "E-learning”, “Technology Enhanced learning” and other terms that are often used synonymously are buzzwords in the current didactic discussion. Several of our results show that these forms of learning can potentially be very motivating for learners between 15 and 19 years. We did however, also find that the motivation gain through the use of New Media is not as big and as durable as theory sometimes suggests. In our opinion, the expectations regarding Blended Learning have to be put into perspective. One of the main arguments for Blended Learning - the possibility to learn "anytime and anywhere" - has to at least be questioned. Several other "road blocks" that prevent successful Blended Learning to take place also exist. Learning Management Systems are not yet up to learners' expectations. Teachers' and students' competences need to be improved and the local parameters at many schools are less than ideal.

The good news is that careful planning and appropriate measures can remove some of these "road blocks". Our aim was to identify factors that prevent or hinder technology enhanced learning processes and to make suggestions what can be done to eliminate these problems. We thereby want to inspire further discussion and inquiry into this topic.

It must be pointed out that only about 50 per cent of the collected data has yet been processed. It is thus too early to present final results. Glimpses into the remaining material show that the quality of the material from project year two is substantially higher than of that from year one. More results and further evidence for the presented hypotheses can thus be expected in the near future.

\section{REFERENCES}

[1] H. Altrichter and P. Posch, Lehrer erforschen ihren Unterricht: eine Einführung in die Methoden der Aktionsforschung. Bad Heilbrunn, 1990.

[2] K.-H.Arnold, U. Sandfuchs and J. Wiechmann (eds.), Handbuch Unterricht. Bad Heilbronn 2009.

[3] Babnik et al., Technologieeinsatz in der Schule. Zum Lernen und Lehren in der Primar- und Sekundarstufe. In: M. Ebner and S. Schön (eds.) 2010: L3T. Lehrbuch für Lernen und Lehren mit Technologien. Ein interdisziplinäres Lehrbuch, , 2010. Online: http://l3t.tugraz.at/index.php/LehrbuchEbner10/issue/current/show Toc. [2012-04-12].

[4] J. Bofinger, Neue Medien im Fachunterricht. Eine empirische Studie über den Einsatz neuer Medien im Fachunterricht an verschiedenen Schularten in Bayern. Donauwörth, 2004.

[5] S. Borg, The research journal: a tool for promoting and understanding researcher development. In: Language Teaching Research, April 2001, 5,2: pp. 156-177. Online: http://ltr.sagepub.com/content/5/2/156.full.pdf+html [2012-0412].

[6] BmUKK, Die acht Zielvereinbarungen für "eLSA-Modellschulen. Wien, 2012. Online: http://elsa20.schule.at/projektgrundlagen/ projektziele/ [2012-04-12].
[7] T. Dresing, and T. Pehl, Praxisbuch Transkription. Regelsysteme, Software und praktische Anleitungen für qualitative ForscherInnen. Marburg, 2011. Online: www.audiotranskrip tion.de/Praxisbuch-Transkription.pdf [2012-07-04].

[8] U.-D. Ehlers, Qualität im E-Learning aus Lernersicht. Grundlagen, Empirie und Modellkonzeption subjektiver Qualität. Univ. Diss. Bielefeld, 2004.

[9] B. Glaser and A. Strauss, Grounded Theory : Strategien qualitativer Forschung. Bern, 2010.

[10] G.F. Hoban, Teacher Learning for Educational Change: A Systems Thinking Approach (Professional Learning). Buckingham, 2002.

[11] U. Höbarth, Konstruktivistisches Lernen mit Moodle: Praktische Einsatzmöglichkeiten in Bildungsinstitutionen. Hülsbusch, 2010.

[12] L. Keller and A. Schober, Endverwendungsnachweis zum Projekt SPA/03-041/LIFE eQuality?. Innsbruck, 2012. Online: http://www3.edumoodle.at/geoibk/login/index.php [2012-08-31].

[13] L. Keller and A. Schober, „LIFE eQuality“ - Beginn eines Projekts zur Untersuchung der Lebensqualität von Jugendlichen durch Jugendliche in vier Alpenregionen. In: Innsbrucker Geographische Gesellschaft (ed.): Innsbrucker Jahresbericht 2008-2010 Innsbruck: 2011 a pp. 188-201.

[14] L. Keller and A. Schober, “LIFE eQuality?” - Teenagers' Inspiring Research into Quality of Life. In: Borsdorf et al: Conference Proceedings Managing Alpine Future II. Innsbruck: 2011 , pp. 446-456.

[15] Market Institut OÖ, BIMEZ KinderMedienStudie. In: Bundesministerium für Unterricht, Kunst und Kultur (ed.): medienimpulse -Beiträge zur Medienpädagogik / Nr.60, 2007. Online: http://daten.bimez.at/uploads/media/pdf/medienpaedago gik/kinder_medien_studie07/studie_gesamt.pdf [2012-04-12].

[16] K. Mayr, P. Resinger and M. Schratz, E-Learning im Schulalltag. Eine Studie zum Einsatz moderner Informations- und Kommunikationstechnologien im Unterricht. Bad Heilbrunn: Klinkhardt, 2009.

[17] Medienpädagogischer Forschungsverbund West (ed.), JIM Studie 2011. Jugend, Information, (Multi-) Media. Stuttgart: Mpfs, 2011.

[18] A. Neyer, Projektevaluation „LIFE 'Quality?“ - Analyse der Lernplattformnutzung eines Sparkling Science Projekts. Diploma Thesis. Innsbruck, 2012.

[19] M. Prensky, Digital Natives, Digital Immigrants. In: On The Horizon. Bradford: 2001, pp. 1-6.

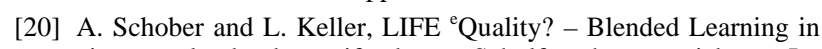
einem länderübergreifenden Schulforschungsprojekt. In: Hamburger eLMAGAZIN. Hamburg, 2011, pp. 61-62. Online: http://www.uni-hamburg.de/eLearning/eCommunity/Hamburger eLearning_Magazin/eLearningMagazin 06.pdf [2012-10-17].

\section{AUTHORS}

Alexander Schober was a research assistant at the department for Geography at Innsbruck University in Innsbruck, Austria. He is now a teacher at the BG/BRG Sillgasse in Innsbruck, Austria. (a.schober@tsn.at).

Lars Keller is with the department for Geography at Innsbruck University in Innsbruck, Austria. (lars.keller@uibk.ac.at).

This work was supported in part by the Austrian Federal Ministry of Science and Research (Bundesministerium für Wissenschaft und Forschung) Received 17 October 2012. Published as resubmitted by the authors 7 November 2012. 